NASA Technical Memorandum 103183

AIAA-90-4010

\title{
Effect of Acoustic Excitation on Stalled Flows Over an Airfoil
}

K.B.M.Q. Zaman

Lewis Research Center

Cleveland, Ohio

Prepared for the

13th Aeroacoustics Conference

sponsored by the American Institute of Aeronautics and Astronautics

Tallahassee, Florida, October 22-24, 1990 


\title{
EFFECT OF ACOUSTIC EXCITATION ON STALLED FLOWS OVER AN AIRFOIL
}

\author{
K.B.M.Q. Zaman \\ National Aeronautics and Space Administration \\ Lew is Research Center \\ Cleveland, $\mathrm{OH} 44135$
}

Abstract

The effect of acoustic excitation on poststalled flows over an airfoil, i.e., flows that are fully separated from near the leading edge, is investigated. The excitation results in a tendency towards reattachment, which is accompanied by an increased lift and reduced drag, al though the flow may still remain fully separated. It is found that with increasing excitation amplitude, the effect becomes more pronounced but shifts to a Strouhal number which is much lower than that expected from linear, inviscid instability of the separated shear layer.

\section{Nomenc la ture}

$\mathrm{C}_{\ell}$

c

$\mathrm{f}_{\mathrm{p}}$

$\mathrm{R}_{\mathrm{C}}$

St

$\mathrm{S}_{\mathbf{u}}$

$\langle U\rangle$

$U, V$

$\left\langle U_{m}\right\rangle$

$\mathrm{U}_{\infty}$

$\left\langle u^{\prime}\right\rangle,\left\langle u_{f}^{\prime}\right\rangle$

$\left\langle u_{r}^{\prime}\right\rangle$

$u^{\prime}, v^{\prime}, w^{\prime}$

$x^{\prime}$

$\mathrm{x}, \mathrm{y}, \mathrm{z}$

$\mathrm{y}^{\prime}$

$\alpha$

(1) lift co-efficient

chord of airfoil

excitation frequency

chord Reynolds number

Strouhal number, $f_{p^{c}} / U_{\infty}$

one dimensional spectrum of $\left\langle u^{\prime}\right\rangle$

mean velocity measured with a single hot wire approximating $\left(U^{2}+V^{2}\right)^{1 / 2}$

mean velocities in $x, y$ directions, respectively

maximum $\langle U\rangle$ just outside the boundary layer

free-stream U

r.m.s. total and fundamental fluctuation in the direction of $\langle U\rangle$, as measured by a single hot wire

$\equiv\left(u_{r}^{\prime 2}+v_{r}^{\prime 2}\right)^{1 / 2}$

r.m.s. velocity fluctuations in $x, y, z$ directions; Subscript $r$ denotes values at reference location

streamwise distance from leading edge

streamwise; transverse and spanwise coordinates

transverse distance from airfoil surface

angle of attack

momentum thickness

\section{Introduction}

The effect of acoustic excitation on flow separation over airfoils was studied previously by several investigators.1-12 In Ref. 10, the general effect over a large $\alpha$-range was investigated addressing such questions as the roles of the tunnel resonance and the instability of the boundary layer in the process. Differences were observed in the effect depending on the $\alpha$-range. At low $\alpha$, laminar boundary layer separation occurred - a condition which aggravated with decreasing $R_{C}$. It was found subsequently, 12 that the laminar separation could be effectively reduced by a small amplitude excitation, within the $R_{C}$ range covered, when the parameter $S t / R_{C}{ }^{1 / 2}$ corresponding to $f_{p}$ fell in the range, 0.02 to 0.03 . In this case, the opt $i-$ mum effect apparently occurred when the excitation frequency matched the instability frequency of the separated shear layer. Around the onset of static stall $\left(\alpha \approx 15^{\circ}\right)$, for the airfoil under consideration, a transitory stall occurred at an unusually low frequency. 11 The effect of acoustic excitation on this phenomenon was rather complex and depending on the range of $f_{p}$ the low frequency oscillation could either be augmented or suppressed. The excitation under certain conditions in this case actually decreased the lift coefficient. In comparison, the excitation at large $\alpha$, i.e., in the poststalled case, consistently increased the $C_{l}$ but the effect was noted to be strongly dependent on the excitation amplitude. 2,10

In the present paper, attention is focussed on the post-stalled flows. As indicated earlier, these flows are defined as ones that are fully stalled, i.e., fully separated from near the leading edge. In contrast to the laminar separation, the separated shear layer in this case undergo transition to turbulence while still over the airfoil, or, at sufficiently high $R_{C}$, the separating boundary layer may already be turbulent. However, the angle of attack is large enough so that even the turbulent shear layer cannot reat tach. Most previous excitation studies concerned the post-stall situation. A review reveals an interesting anomaly. The Strouhal number ( $S t$ ) corresponding to the effective excitation is found to vary widely from experiment to experiment. This is listed in Table 1 . Note that between Refs. 3 and 8 , for similar $R_{C}$ and airfoil, there is an order of magnitude difference in the effective St. Between Refs. 9 and 10 the results may be extrapolated to yield an even larger difference in the effective $S t$ for comparable $R_{C}$.

It is apparent that "external" excitation produces the effect at high. St whereas "internal" excitation is effective at lower St. One exception is the result of Ref. 2. "External" excitation typically involved acoustic irradiation with a source away from the airfoil 1-5,10-12 "Internal" excitation, on the other hand, involved direct introduction of velocity perturbation in the flow, e.g., acoustically through slots on the airfoil, 5,7 by vibrating ribbon ${ }^{8}$ or by a vibrating wire placed near the leading edge. 9 In general, a more profound effect of the excitation was observed using internal excitation.

The question that arises naturally is what is the difference between the two methods that produce the effect in such different ranges of $S t$ ? In both cases the perturbation has to act on the instability of the separating shear layer. Nishioka et al.5 
eloquently said. "The instability of the separated shear layer is quintessential as the underlying mechanism which enables the sound waves to suppress the separation." However, the instability mechanism responsible for the effect in the present case may be complex due to the presence of the wall as well as nonlinearity associated with the high amplitudes. In fact, the main result of the present experiment is an amplitude dependence of the excitation effect as discussed in the following. It will be shown that with increasing amplitude the effect is more pronounced but shif ts to a lower $S t$, which, al though remaining unexplained reconciles the anomaly noted above.

"External" excitation is used in the present study but the amplitude is varied in a controlled manner within the constraints of tunnel resonances. Parametric dependence of the excitation effect on frequency and amplitude is studied for three Reynolds numbers. The flow field for a specific large amplitude excitation case is then documented in detail.

\section{Experimental Facility}

The experiments are carried out in the NASA Lew is Research Center Low Speed Wind tunnel, which has been described in detail in Refs. 11 and 12 . The schematic of the test section is reproduced from Ref. 12 as Fig. 1. The maximum tunnel speed is about $12 \mathrm{~m} / \mathrm{sec}$ with free stream turbulence intensity less than 0.1 percent. A two-dimensional airfoil (LRN (1)-1007) with chord $\mathrm{C}=12.7 \mathrm{~cm}$ and aspect ratio of six is used in the experiment; the cross-sectional shape of the airfoil is shown by the inset in Fig. 2. Two acoustic drivers and a $40.6 \mathrm{~cm}$ woofer are used for the excitation, covering a wide frequency range of $15 \mathrm{~Hz}$ to $15 \mathrm{kHz}$. Only one speaker is used at a time; for $f_{p}<700 \mathrm{~Hz}$ the woofer is used, for $f_{p}>700 \mathrm{~Hz}$ one of the acoustic drivers is used. A crossed hot-film probe (DISA 55R53) is used to measure velocity fluctuation amplitudes ( $u^{\prime}$ and $v^{\prime}$ ), at a reference location about $0.4 \mathrm{c}$ upstream of the airfoil leading edge. The resultant of $u^{\prime}$ and $v^{\prime}$ measured at this fixed location is denoted as the reference amplitude parameter $\left\langle u_{r}^{\prime}\right\rangle$, which is expressed as percentage of $U_{\infty}$. A computer controlled traversing mechanism is used to move a single hot wire to measure the velocity field around the airfoil. The coordinate origin is at the tunnel midheight $(y=0)$ and midspan $(z=0)$ and at the airfoil midchord $(x=0)$. For convenience, the streamwise coordinate $\left(x^{\prime}\right)$ for some data has been referenced to the airfoil leading edge. Lift is measured by a balance mechanism; for further details of the experimental procedure the reader may consult Refs. 11 and 12 .

\section{Results and Discussion}

\subsection{Ampli tude Effect}

First, let us briefly review the essential features of the tunnel resonance characteristics, the data on which have been presented in Ref. 12. At low $f_{p}$ longitudinal resonances are encountered. Thus, for $f_{p} \leqslant 280 \mathrm{~Hz}$, primarily $u^{\prime}$ fluctuations are induced which are uniform over the tunnel cross section. With increasing $f_{p}$ increasingly complex resonances occur characterized by nonuniform amplitude distributions over a given cross section of the tunnel. However, well defined excitation conditions are achieved at certain higher $f_{p}$ 's. One such case is at the fundamental cross resonance at $3+2 \mathrm{~Hz}$. Large $v^{\circ}$, uniform in the spanwise direction, is induced at this $f_{p}$ in the vicinity of the airfoil. Because of the availability of large amplitudes, some detailed measurements were conducted at this $\mathrm{f}_{\mathrm{p}}$.

Figure 2 shows the lift coefficient $\left(C_{Q}\right)$ variation with the angle of attack $(\alpha)$ with and without excitation at $342 \mathrm{~Hz}$. The amplitude of excitation is large and the lift is found to increase over the entire $\alpha$-range covered. For the flow under consideration, the low frequency transitory stall is induced by the excitation approximately in the $\alpha$ range of $14^{\circ}$ to $16^{\circ}$; this is accompanied by an unusual increase in the $C_{l} .11$ However, in this paper the excitation effect is studied for the fully stalled condition which occurs in the range $\alpha \geq 16^{\circ}$.

The excitation amplitude effect is shown for several $\alpha$ in Fig. 3. Large gains are achieved at the lower $\alpha$ but the effect diminishes with increasing $\alpha$. Nevertheless, perceptible increase in $C_{l}$ occurs even at $\alpha=30^{\circ}$. Note the "saturation" and the subsequent "breakdown" in $\mathrm{C}_{\ell}$ with increasing amplitude in the range $16^{\circ}<\alpha<20^{\circ}$. This aspect will be further addressed in section 3.3 .

For $\alpha=18^{\circ}, \mathrm{C}_{l}$ versus $\left\langle\mathrm{u}^{\prime}{ }_{\mathrm{r}}\right\rangle$ was measured for a large number of $f_{p}$ for a given $R_{C}$. Sample data are shown in Fig. 4 for three values of $R_{C}$. The Strouhal number corresponding to each curve is indicated. Several of the curves are terminated on the right by the limitation in the available amplitude from the loudspeaker in use. Inspection should reveal that for constant amplitude at a given $S t$, comparable gains are achieved at all three $R_{C}$.

The variations of $C_{\ell}$ with $S t$ are cross plotted from data similar to those in Fig. 4, in Figs. 5(a) to (c) for the three $R_{C}$. These are hand smoothed curves through the data, some of the curves at high amplitudes are based on only three data points. However, it is clear that with increasing amplitude large increase in $C_{\ell}$ occurs but the effect shifts progressively to lower $S t$.

For the amplitudes covered the optimum increase is found to occur in the range $2 \leqslant S t \leqslant 5$. This $S t$ range is substantially lower than the corresponding range for the linear, inviscid instability of the separated shear layer. The latter range can be inferred from hot-wire surveys near the leading edge. The time trace in Fig. 6(a) shows a high frequency periodicity superimposed on the low frequency fluctuations. The high frequency fluctuation characterizes the $u^{\prime}$-spectrum by a broadband hump centered around $2 \mathrm{kHz}$ as shown in Fig. 6(b). This represents the (Kelvin-Helmholtz) instability frequency of the separated shear layer for the flow under consideration. Al though there is subjectiveness, this is a simple way to experimentally determine the range of the shear layer instability frequency; a similar method was also used in references 6 and 13. The momentum thickness $(\theta)$ of the separated shear layer at $x^{\prime} / c=0.03$ was measured to be $0.07 \mathrm{~mm}$. The frequency $2 \mathrm{kHz}$ thus corresponds to a nondimensional value, $\mathrm{f} \Theta / \mathrm{U}_{\infty} \approx 0.016$. This agrees with stability prediction for maximally amplified disturbances for a zero pressure gradient 
shear layer. (As discussed later, the pressure gradient in the separated, unexcited flow is indeed smal1). Thus, the above data confirms that the spectral hump around $2 \mathrm{kHz}$ is due to the initial shear layer instability.

Referring back to Fig. 5(b), one finds that $2 \mathrm{kHz}$ corresponds to $\mathrm{St} \approx 30$ (indicated by the arrow) in contrast to the value $S t \approx 4$ producing the optimum effect. Obviously, for $R_{C}=10^{5}$ in Fig. 5(c) this difference should be even larger. A similar observation was made in Ref. 13 for the excitation effect on the separation bubble over the blunt end of a cylinder placed parallel to the flow. As to be discussed further in section 4, the excita$t i o n$ was found to be effective when the forcing frequency was much lower than the Kelvin-Helmholtz instability frequency of the initial shear layer. A similar trend was also observed in Ref. 5 for the flow over a flat plate model at large $\alpha$. Thus, the linear instability of the separated shear layer does not appear to be the primary mechanism through which the optimum excitation effect is achieved. Apparently, nonlinear effects play a significant role. Viscous effects could also be important as there is indication of a separation bubble near the leading edge (section 3.3). No analysis is presently available to address the observed effects sat is actorily.

The shift of the optimum effect to lower St with increasing amplitude should explain the anomaly discussed in section one. With "external" excitation typically lower amplitudes are induced. For example, in Refs. 1 and 10 it is estimated from the sound pressure level data that approximately 0.1 percent amplitudes, in terms of the present notation $\left(\left\langle u_{r}^{\prime}\right\rangle / U_{\infty}\right)$ were used. One can roughly

estimate the amplitude to be close to 2 percent in Ref. 2 for the data mentioned in Table 1 . Thus, the large effect at low St observed in the latter work $\mathrm{fits}$ with the data trend found in the present experiment. For the internal excitation cases none of the references clearly provide velocity amplitude data but it is reasonable to assume that they are large.

\subsection{Flow Field Detail}

In the following flow field data are presented for a case of excitation at $R_{C}=75000$, with $f_{p}=342 \mathrm{~Hz}$ and $\left\langle u_{r}\right\rangle / U_{\infty}=1.5$ percent. The mean velocity profiles measured at different chordwise locations on the upper surface are shown in Fig. 7. These data are measured with a single hot-wire and there is error due to hot-wire rectification in regions of reverse flow near the wall. In the range where $\langle U\rangle /\left\langle U_{m}\right\rangle\langle 0.5$, the data have been corrected by an algorithm which is chosen to roughly approximate the probability distribution of reverse flow in comparable flow fields. 14 The correction function $g(y)$ is defined as.

$$
\begin{aligned}
\left\langle U_{\text {corrected }}\right\rangle & =\left\langle U_{\text {measured }}{ }^{*}\left(1-2 g\left(y^{\prime}\right)\right)\right. \\
g\left(y^{\prime}\right) & =1-1 /\left(1+\exp \left(2^{*}\left(\left(y^{\prime} 0.5^{-y^{\prime}}\right) / y^{\prime} 0.5^{*} 4-2\right)\right)\right)
\end{aligned}
$$

so that $g(0) \approx 1$ and $g\left(y^{\prime} 0.5\right) \approx 0$. However, in the range where the correction is done (indicated by the shaded regions) the data should be considered only as qualitative. The composite plot of Fig. 7 provides a perspective on the effect of the excitation over the entire upper surface.
The corresponding r.m.s. fluctuation intensity profiles are shown in Fig. 8. (Data corresponding to the shaded regions of $\mathrm{Fig}, 7$ should be considered as qualitative). [n both Figs. 7 and 8 the boundary layer is found to thicken near the leading edge under the excitation. But downstream of $x^{\prime} / c \approx 0.1$, the effect of the excitation is to reduce the transverse extent of the separated region.

The locii of the $0.7\left\langle\mathrm{U}_{\mathrm{m}}\right\rangle$ point with and without excitation, derived from profiles as in Fig. 7 , are shown in Fig. $9(a)$. The corresponding distribu$t$ ions of $\left\langle U_{m}\right\rangle$ are shown in Fig. $9(b)$. The reduction in the separated region under the excitation and the accompanied change in the $\left\langle U_{\mathbb{m}}\right\rangle$ distribution (and thus in the static pressure distribution) should be clearly evident from these data. With reference to the discussion on Fig. 6, note that $\left\langle\mathrm{U}_{\mathrm{m}}\right\rangle$ is practically constant shortly downstream of the leading edge, thus indicating a near zero pressure gradient for the separated flow in the unexcited case.

It was noted in Fig. 8 that the fundamental r.m.s. amplitude becomes very small downstream of $\mathrm{x}^{\prime} / \mathrm{c} \approx 0.2$. The amplitude $\left\langle\mathrm{u}_{\mathrm{f}}^{\prime}\right\rangle$ (at 342 ) $\mathrm{Hz}$ was measured along the $0.7\left\langle\mathrm{U}_{\mathrm{m}}\right\rangle$ points and shown in Fig. $9(\mathrm{c})$. These data approximately represent the $\left\langle u_{f}^{\prime}\right\rangle$-maxima distribution. Clearly, the amplitude becomes very large shortly downstream of the leading edge. The peak occurs at about 3 percent chord location. But immediately downstream the flow breaks own into turbulence obliterating the fundamental.

The following point may be made based on the data of Fig. 9(c). Consider the data trend of Fig. 5(b) again. Recall that the initial shear layer instability corresponds to $S t \approx 30$ whereas the optimum effect takes place at an order of magnitude lower St. One could hypothesize that the large effect at the low $S t$ should be due to an effective excitation of the thicker shear layer downstream of the leading edge. This seemed plausible based on the knowledge of excitation effect on free jets. In the latter case, it is known that large amplitude excitation at frequencies much lower than the initial shear layer instability frequency can profoundly excite the jet. The lower frequency disturbance is maximally amplified by the shear layer downstream and apparently corresponds to the linear instability of the thicker shear layer there.15 The fundamental amplitude in that case grows to a maximum in the vicinity of that location. It was thought that a similar effect might be taking place in the present flow. However, the data of Fig. 9(c) bears evidence to the contrary. Clearly, the amplification is taking place right around the leading edge rather than at a farther downstream location.

$$
\text { Also shown in Fig, } 9(c) \text { are }\left\langle u_{f}^{\prime}\right\rangle \text { data for }
$$

the lower shear layer emanating from the trailing edge. Obviously, the lower shear layer has also been excited similarly as compared to the upper one. However, it is reasonable to believe that this has very little effect on the airfoil performance. Figure $9(a)$ clearly indicates that the mean flow field is affected primarily in the upper shear layer causing the observed improvement in the airfoil performance. 
Traces of the velocity signal at different streamwise location are shown in Fig. 10. At each $x^{\prime}$ the data represent the transverse location where $\left\langle u_{f}\right\rangle$ is approximately the maximum; the ver-

tical scale for each trace is the same. As the perturbation negotiates the leading edge the amplitude grows rapidly. At $x^{\prime} / c=-0.05$ the fundamental (r.m.s.) is less than 2 percent of $U_{\infty}$ but becomes nearly 40 percent at $x^{\prime} / c=0.03$. Note that at the reference location, at $\mathrm{x}^{\prime} / \mathrm{c} \approx-0.4 \mathrm{c}, \mathrm{v}_{\mathrm{f}}^{\prime} / \mathrm{U}_{\infty}=$ 1.5 percent but $u_{f}^{\prime} / U_{\infty}$ is nearly zero. But downstream of the leading edge. $u_{f}^{\prime}$ becomes large and $v_{f}^{\prime}$ must be nearly zero due to the proximity of the wall. ( $\left\langle u_{f}^{\prime}\right\rangle$ should nearly equal $u_{f}^{\prime}$ at most measurement locations). Turbulent breakdown is apparent at $\mathrm{x} / \mathrm{c}=0.07$ commensurate with the data of Fig. 9. Figure 10 also indicate an absence of significant vortex pairing activity. In both references 5 and 13 evidence of vortex pairing was reported. In the experiment on the effect of excitation on the flow over a backward facing step, 16 significant pairing activity was also noted. The excitation amplitude in the present experiment is apparently much larger and it is clear from Fig. 10 that the fundamental undergoes a large growth and subsequent breakdown with no evidence of pairing that would result in a frequency halving.

\subsection{The "Saturation" in Lift Enhancement}

Referring back to Fig. 3 recall that for the low $\alpha$ cases the $C_{\ell}$ variation indicated a saturation and subsequent breakdown with increasing excitation amplitude. This behavior was investigated further. The hot wire was placed at $\mathrm{x}: / \mathrm{c}=0.3$ at a transverse location where the mean velocity read was approximately $0.3 \mathrm{U}_{\infty}$. As the excitation was turned on the separated shear layer was drawn closer to the surface which manifested in an increase in the mean velocity read by the hot wire. The variation of the mean velocity, read at the fixed location, with $\left\langle u_{r}^{\prime}\right\rangle$ is shown in Fig. 11. Note that the variations for the three $\alpha$ cases are commensurate with the data trends in Fig. 3 . The "breakdowns" in the curves occur at approximately the same amplitude levels. These data independently confirm the trend observed in Fig. 3 .

The airfoil was now held at $\alpha=18^{\circ}$ and the flow field before and after the "breakdown", (at amplitudes of 1.8 percent and 2.4 percent respectively), were investigated. When switched from one to the other amplitude, any anomaly in the operation of the facility was looked for. All other parameters appeared to remain the same. The spectra of the reference velocity signals ( $u_{r}^{\prime}$ and $v_{r}^{\prime}$ ) indicated "pure tone" excitation at either amplitude with higher harmonics no larger than 2 percent of the fundamental.12 Thus, the "breakdown" at the higher amplitude was not due to some sort of distortion in the imparted excitation.

For the two amplitudes, the locii of the $0.7\left\langle U_{m}\right\rangle$ points (as in Fig. $9(a)$ ) as well as the corresponding $\left\langle u_{f}^{\prime}\right\rangle$, were measured. These data are shown in Fig. ${ }^{12}$. The $\left\langle u_{f}^{\prime}\right\rangle$ variation does not seem to shed any light as to why the lift reduced at the higher amplitude. Not unexpectedly, for the 2.4 percent amplitude, $\left\langle u_{f}^{\prime}\right\rangle$ grows to a higher level and stays high everywhere relative to the other case. The $y_{0.7}$ data, however, clearly show that the flow opens up downstream at the higher amplitude reconciling with the observed reduction in the lift. Near the leading edge, the $y_{0} .7$ data indicate the existence of a separation bubble which is more prominent at the lower amplitude case. At 2.4 percent amplitude, the bubble appears to get "squashed" which apparently leads to the change in the aerodynamic characteristic of the suction surface resulting in the lower lift.

\section{Concluding Remarks}

Experimental results on the effect of acoustic excitation on post-stalled flows at large $\alpha$ are summarized in this paper. It is shown that as the amplitude of excitation is increased large increase in the lift is achieved but the optimum effect shifts progressively to lower Strouhal number. The Strouhal number yielding the optimum effect can be orders of magnitude lower than that corresponding to the linear, inviscid instability of the separated shear layer.

The flow field data show that the perturbation is amplified shortly downstream of the leading edge reaching a very high level. But farther downstream the flow becomes turbulent and the fundamental at the excitation frequency is hardly detectable. At $\alpha$ values close to static stall condition, the increase in the lift with increasing excitation amplitude undergoes an abrupt "breakdown". This behavior is found to be associated with a separation bubble, occurring under the excitation, near the leading edge. At high excitation amplitude the bubble is broken up or reduced in size resulting in the observed "breakdown" in the lift.

As mentioned in the text, in a relevant experiment on the separation bubble over the blunt end of a cylinder placed parallel to the flow, 13 a similar observation was made on the excitation effect. The effective excitation, resulting in a smaller bubble with accompanying reduction in drag, occurred at a frequency which was much lower than the KelvinHelmholt $z$ instability frequency. It was hypothesized that a separation bubble is characterized by $a$ "shedding type instability" whose frequency $\left(f_{s}\right)$ scales with the bubble height $(h)$ and the freestream speed outside the bubble $\left(U_{m}\right)$ such that $\mathrm{f}_{\mathrm{S}} \mathrm{h} / \mathrm{U}_{\mathrm{m}} \approx 0.08$. It was thought to be similar to vortex shedding from a bluff body but due to the presence of the wall the interaction was with the "image vortices" and thus, the nondimensional frequency was roughly one-half that observed in the normal bluff body shedding. The data indicated that the optimum excitation effect took place when the nondimensional frequency was 2 to 4 times higher than the value noted above. The present results may be reviewed in this light. Referring back to the velocity profile at $\mathrm{x}^{\prime} / \mathrm{C}=0.03$ in $\mathrm{Fig} .7,\left(\mathrm{~h} \approx 3 \mathrm{~mm}, \mathrm{U}_{\mathrm{m}} \approx 1.6 \mathrm{U}_{\infty}\right)$, a nondimensional value of about 0.08 is obtained for the effective frequency. This value, of course, is subjective and should vary depending on the measurement location but is interestingly close to the value of the so called "shedding instability" frequency. A separation bubble oscillation has been reported by others also (e.g., Ref. 14). However, the concept of an associated instability and its role in the excitation process deserve further investigation in the future. 
The appearance of the separation bubble, which is characteristic of low $R_{C}$ flows, raises the question if the inferences made from the present experiment will be applicable at higher $R_{C}$. Referring back to section 1 , one may classify the poststalled flows into two broad categories. (A) At low $R_{C}$, the separated shear layer is initially laminar, and (B) at high $R_{C}$, the separating shear layer is already turbulent, $\mathrm{R}_{\mathrm{C}} \approx 5 \times 10^{5}$ may be considered as the borderline, 17 although this depends largely on the airfoil shape and the free-stream conditions. The present experiment as well as most of the ones listed in Table 1 deal with class $A$ flows. Certainly, the separation bubble must involve initially laminar shear layer and thus the observed "breakdown" in the 1 if t must be characteristic of only the class a flows. However, the experiment of Ref. 2 involved a class $B$ flow, as a boundary layer trip was used near the leading edge. First, this proves that class $B$ flows can also be excited to improve airfoil performance. This should not be surprising as there is ample proof that excitation can significantly affect an initially fully turbulent shear layer.16,18 Secondly, for the initially turbulent shear layer in class $B$ flows only high amplitude excitation may be expected to be effective; thus, according to the results presented in this paper the effect may be expected to occur only at low values of $\mathrm{Strouhal}$ number.

\section{References}

1. Collins, F.G. and Zelenevitz, J., "Influence of sound upon separated flow over wings," AIAA Journal, Vol. 13, No. 3, Mar. 1975, pp. 408-410.

2. Ahuja, K.K. and Burrin, R.H., "Control of flow separation by sound," AIAA Paper 84-2298, 0ct. 1984.

3. Marchman, J.F., Sumantran, V., and Schaefer, C.G., "Acoustic and Turbulence Influences on Stall hysteresis," AIAA Paper 86-0170, Jan. 1986.

4. Mueller, T.J. and Batill, S.M., "Experimental studies of separation on a two-dimensional airfoil at low Reynolds numbers," AIAA Journal, Vol. 20, No. 4, Apr. 1982 , pp. 457-463.

5. Nishioka, M., Asai, S. and Yoshida, S., "Control of flow separation by acoustic excitation," AIAA Paper 89-0973, Mar. 1989.

6. Huang, L.S., Maestrello, L., and Bryant, T.D. "Separation control over an airfoil at high angles of attack by sound emanating from the surface," AIAA Paper 87-1261, June 1987.

7. Hsiao, F.B., Liu C.F., Shyu J.Y. and Wang, M.R., "Control of wall separated flow by internal acoustic excitation," AlAA Paper 89-0974, Mar. 1989
8. Neuburger D. and Wygnanski I., private communication, "The use of a vibrating ribbon to delay separation on two-dimensional airfoils: some preliminary observations," Workshop on Unsteady Separated Flow, Air Force Academy, July 1987.

9. Bar-Sever A., "Separation Control on an airfoil by periodic forcing", AIAA Journal, Vol. 27 No. 6, June 1989, pp. 820-821.

10. Zaman, K.B.M.Q., Bar-Sever, A. and Mangalam, S.M., "Effect of Acoustic Excitation on the Flow over a Low-Re Airfoil," Lournal of Fluid Mechanics, Vol. 182, Sept. 1987 , pp. 127-148.

11. Zaman, K.B.M.Q., McKinzie, D.J. and Rumsey, C.L., "A natural low-frequency oscillation of the flow over an airfoil near stalling conditions," Lournal of Fluid Mechanics, Vol. 202, May, 1989, pp. 403-442.

12. Zaman, K.B.M.Q, and McKinzie, D.J., "Control of laminar separation over airfoils by acoustic excitation," AlAA Paper 89-0565, Jan. 1989. (Also, NASA TM-101379).

13. Sigurdson, L.W. and Roshko, A., "Controlled unsteady excitation of a reattaching flow," AIAA Pager 85-0552, Mar. 1985.

14. Simpson, R.L., "Two-dimensional turbulent separated f low," AGARD-AG-287-Vol-1, AGARD, Neuilly-Sur-Seine, France, 1985. (Avail. NTIS, AD-A160659).

15. Petersen, R.A., and Samet, M.M., "On the preferred mode of jet instability," Journal of Fluid Mechanics, Vol. 194, Sept. 1988, pp. 153-173.

16. Roos, F.W. and Kegelamn, J.T., "Structure and control of flow over a backward-facing step," Forum on Unsteady Flow Separation, K.N. Ghia, ed., ASME, New York, 1987, pp. 215-223.

17. Mueller, T.J. and Reshotko, E., "Low Reynolds number vehicles," AGARD-AG-288, AGARD, Neuilly-Sur-Seine, France, 1985. (Avail. NTIS, AD-A153233).

18. Crow, S.C. and Champagne, F.H., "Orderly structure in jet turbulence," Journal of Fluid Mechanics, Vol. 48, Pt. 3, Aug. 16, 1971, pp. 547-591. 
Table 1. - Excitation Parameters From Previous Studies

\begin{tabular}{|c|c|c|c|c|c|}
\hline Reference & Airfoil & $\begin{array}{c}\alpha \\
\operatorname{deg}\end{array}$ & $\mathrm{R}_{\mathrm{C}} \times 10^{-5}$ & $\begin{array}{c}\text { Ef fective, } \\
\text { St }\end{array}$ & $\begin{array}{c}\text { Excitation } \\
\text { type }\end{array}$ \\
\hline $\begin{array}{l}\text { Collins and } \\
\text { Zelenevi tz }\end{array}$ & $\begin{array}{l}\text { NACA } \\
2412\end{array}$ & 20 to 24 & 5.3 & 28 to 94 & External \\
\hline $\begin{array}{l}\text { Ahuja and } \\
\text { Burrin }\end{array}$ & ---- & 16 & 5.0 & 2.7 & External \\
\hline $\begin{array}{l}\text { Marchman } \\
\text { et al. } 3\end{array}$ & $\begin{array}{l}\text { Wor tmann } \\
\text { FX63-137 }\end{array}$ & 15 & 2.0 & 27 & External \\
\hline $\begin{array}{l}\text { Neubruger } \\
\text { and } \\
\text { Wygnanski } 8\end{array}$ & $\begin{array}{l}\text { Wor tmann } \\
\text { FX63-137 }\end{array}$ & 16 & 2.0 & 1.8 & $\begin{array}{l}\text { Internal } \\
\text { vibrating } \\
\text { ribbon }\end{array}$ \\
\hline $\begin{array}{l}\text { Hsiao } \\
\text { et al. } 7\end{array}$ & $\begin{array}{l}\text { NACA } \\
63-018\end{array}$ & 18 to 24 & 0.2 to 3.0 & $\approx 2$ & $\begin{array}{l}\text { Internal } \\
\text { acoustic }\end{array}$ \\
\hline $\begin{array}{l}\text { Huang and } \\
\text { Maes tre } 10^{6}\end{array}$ & - & 15 to 20 & 0.35 & $\approx 1$ & $\begin{array}{l}\text { Internal } \\
\text { acoustic }\end{array}$ \\
\hline $\begin{array}{l}\text { Nishioka } \\
\text { et al. } 5\end{array}$ & $\begin{array}{l}\text { Flat } \\
\text { plate }\end{array}$ & 8 to 14 & 0.4 & 3.8 to 27 & External \\
\hline Bar-Sever ${ }^{9}$ & LRN & 20 & 1.5 & 1.5 & $\begin{array}{l}\text { Internal } \\
\text { vibrating } \\
\text { wire }\end{array}$ \\
\hline $\begin{array}{l}\text { Zaman } \\
\text { et al. } 10\end{array}$ & LRN & 18 to 22 & 0.4 to 1.0 & 7 to 40 & External \\
\hline
\end{tabular}

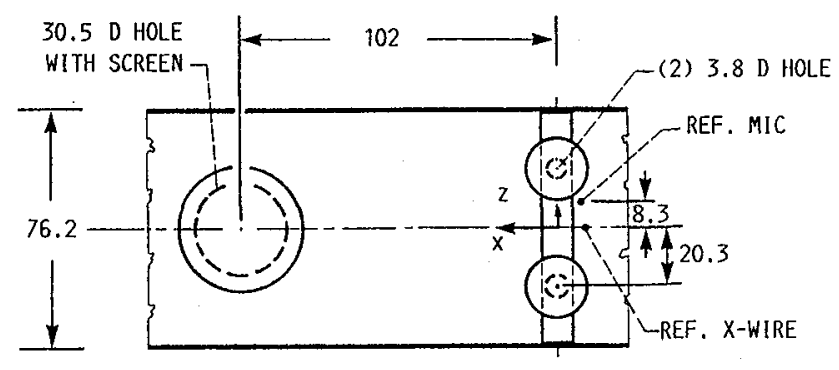

TOP VIEW

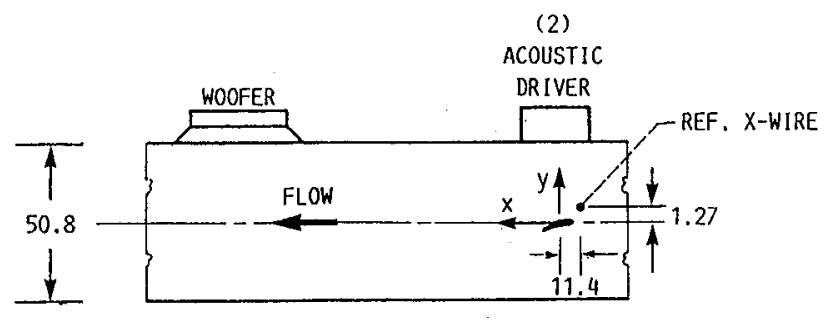

(b)

FIGURE 1. - SCHEMATIC OF WIND TUNNEL TEST SECTION: DIMENSIONS ARE IN CENTIMETERS.

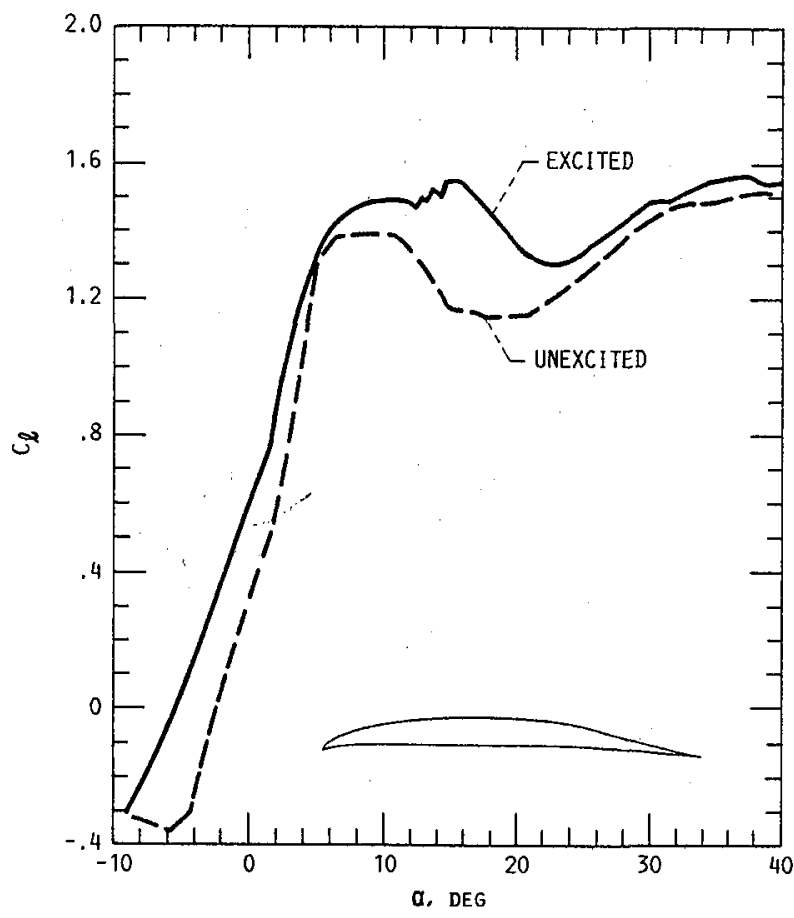

FIGURE 2. $-c_{\ell}$ VERSUS a WITH AND WITHOUT EXCITATION. EXCITATION AT $i_{p}=342 \mathrm{~Hz} \cdot\left\langle U_{r}{ }_{\Gamma}\right\rangle / \mathrm{U}_{\infty}=1.5$ PERCENT: $R_{C}=75000$. 


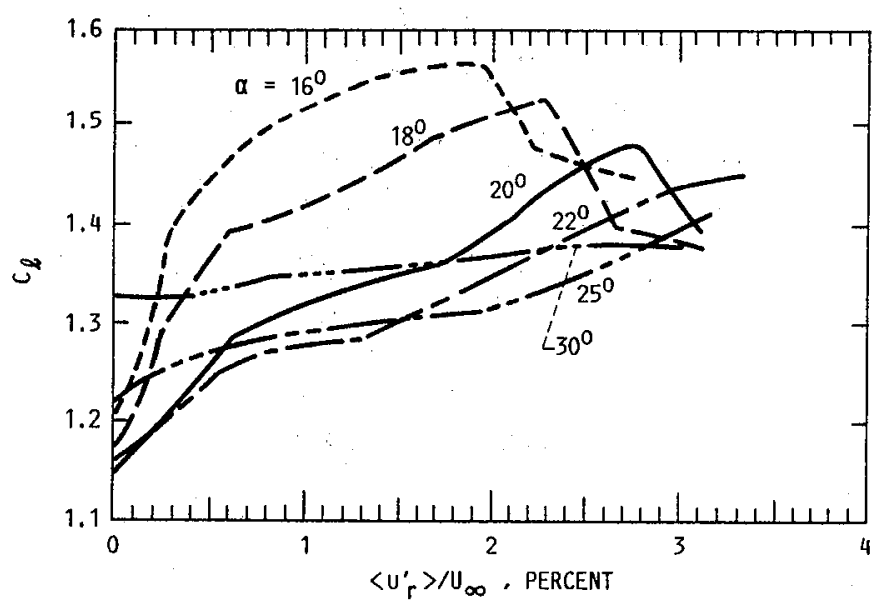

FIGURE $3 .-c_{\ell}$ VERSUS $\left\langle u_{r}^{\prime}\right\rangle / N_{\infty}$ FOR DIFFERENT $a ; f_{p}=342 \mathrm{~Hz}$. $R_{C}=75000$.
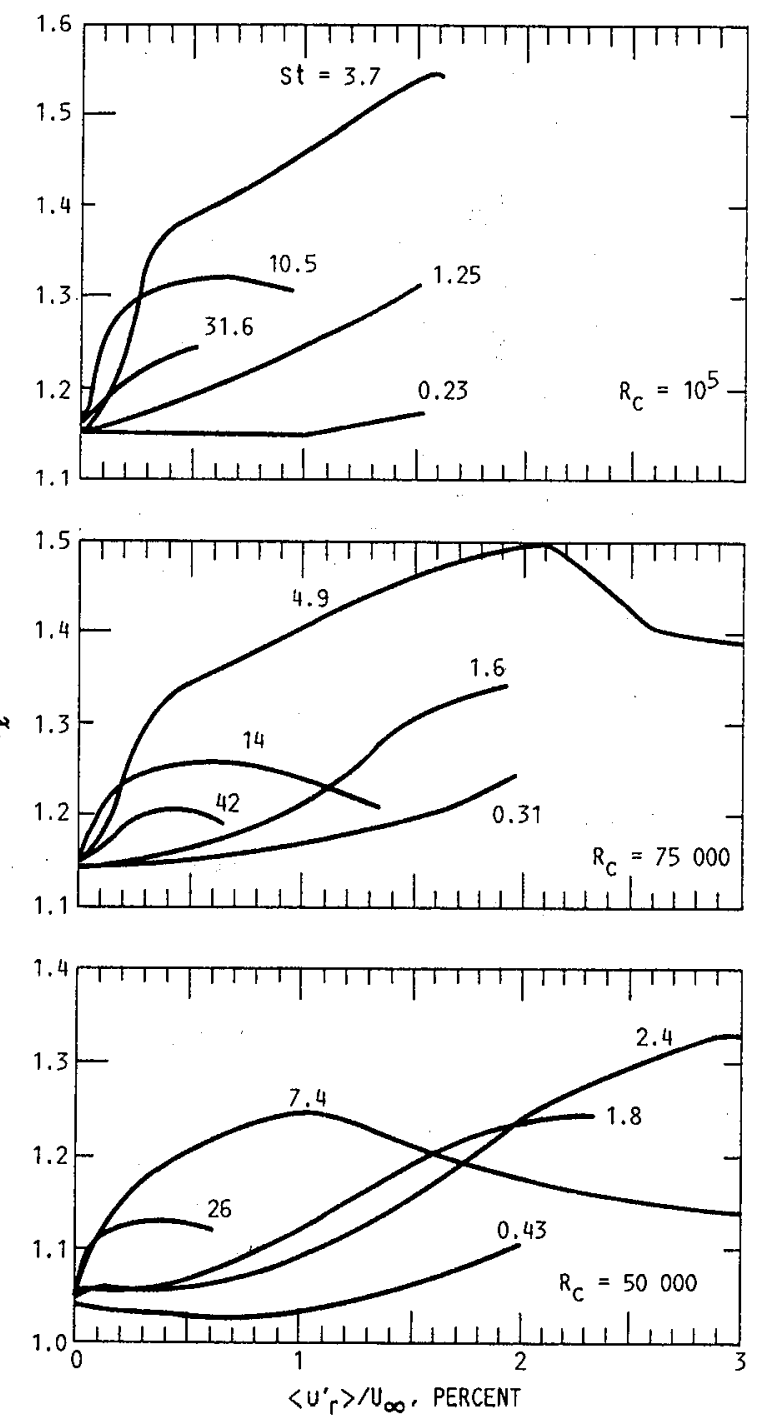

FIGURE 4. $-c_{\ell}$ VERSUS $\left\langle U^{\prime} r\right\rangle / U_{\infty}$ FOR DIFFERENT $S t$. THE THREE SETS OF DATA ARE FOR INDICATED VALUES $O F R_{C}$. 


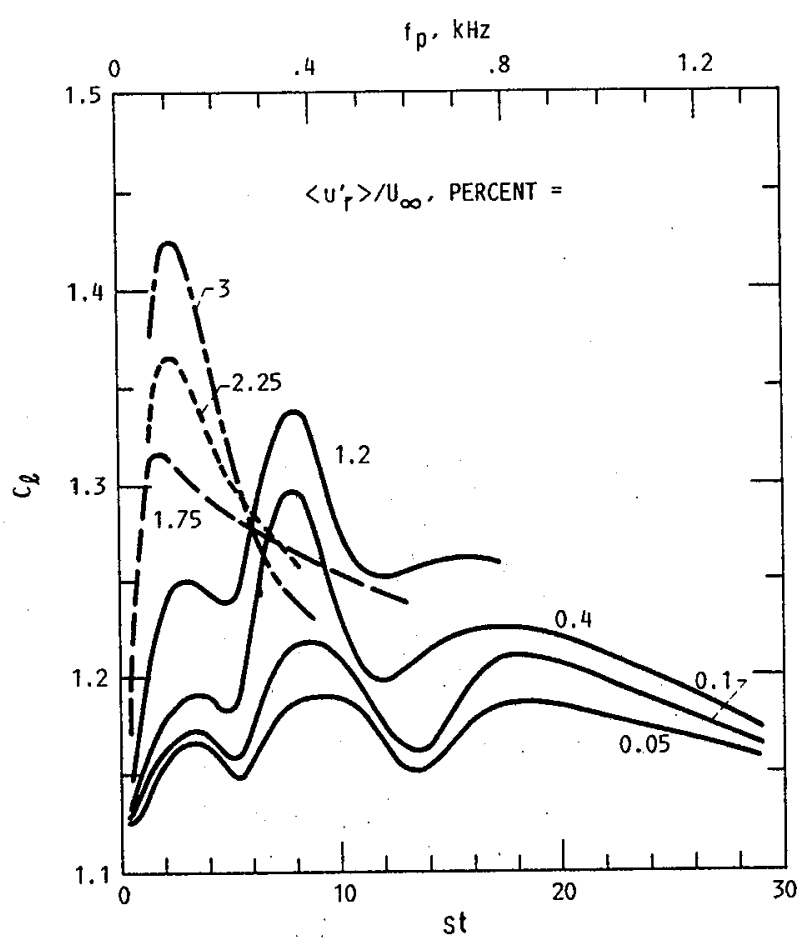

(a) $R_{C}=50000$.

FIGURE 5. $-c_{l}$ VERSUS St FOR DIFFERENT $\left\langle u_{r}^{\prime}\right\rangle / U_{\infty}$.

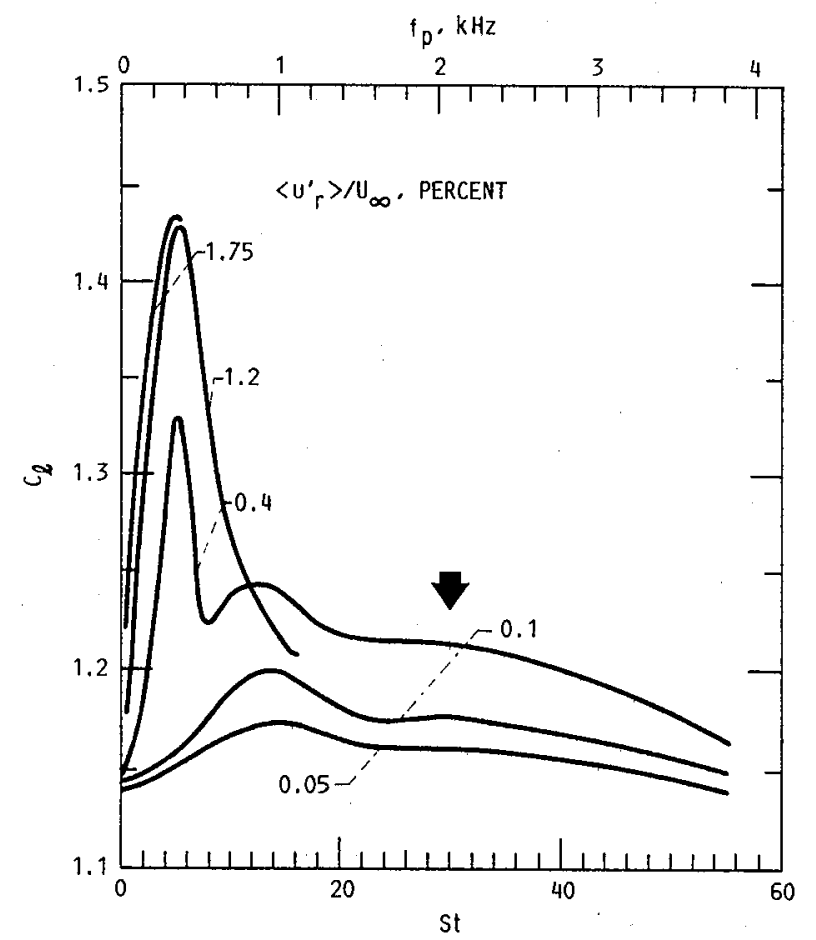

(b) $R_{C}=75000$.

FIGURE 5. - CONTINUED.

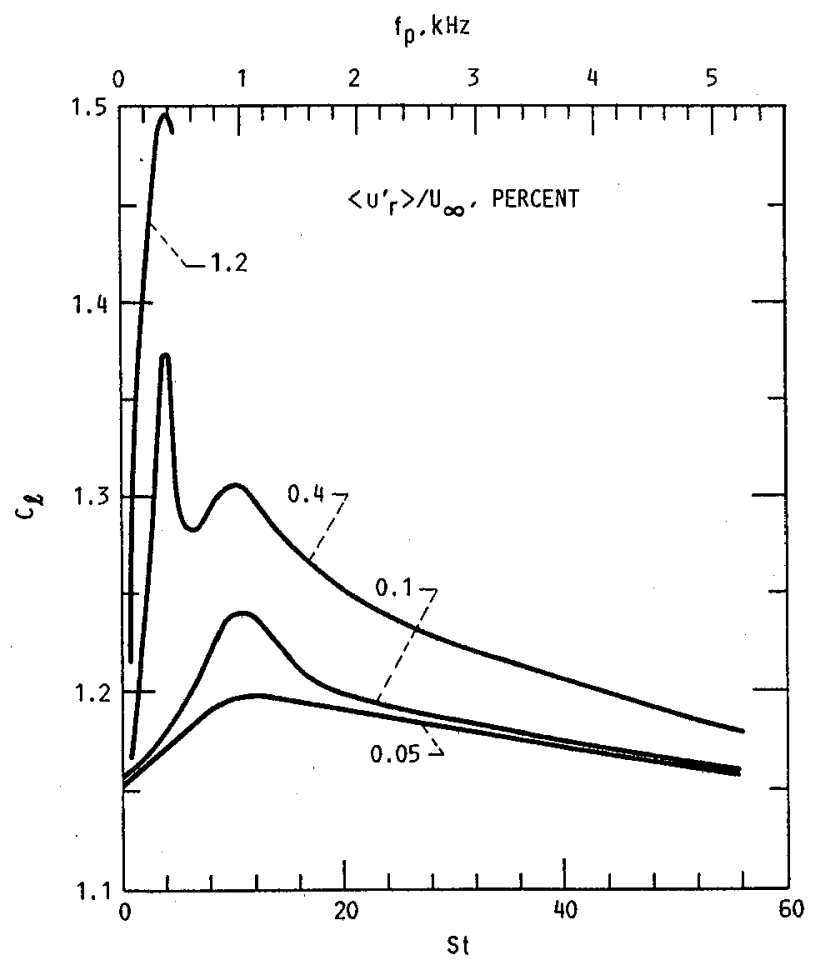

(c) $\mathrm{R}_{\mathrm{C}}=100000$.

FIGURE 5. - CONCLUDED. 


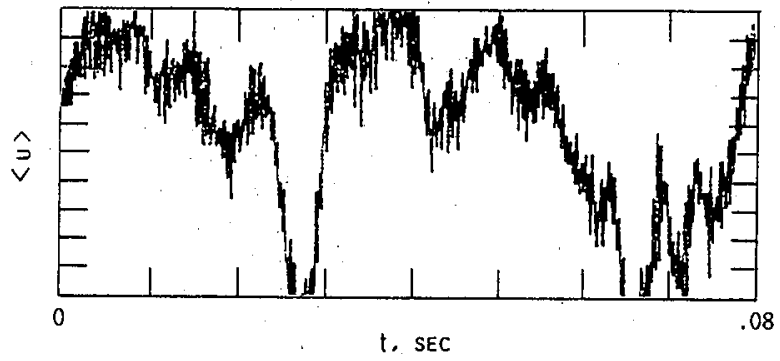

(a) SAMPLE TIME TRACE.

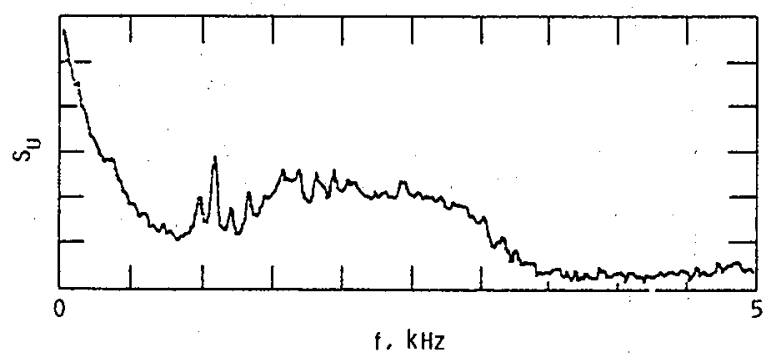

(b) TIME-AVERAGED SPECTRUM.

FIGURE 6. - 〈U〉-FLUCTUATIONS NEAR THE HIGH SPEED EDGE OF THE BOUNDARY LAYER AT $x^{\prime} / c=0.03, a=18^{0}, R_{c}=$ 75 000. NO EXCITATION.
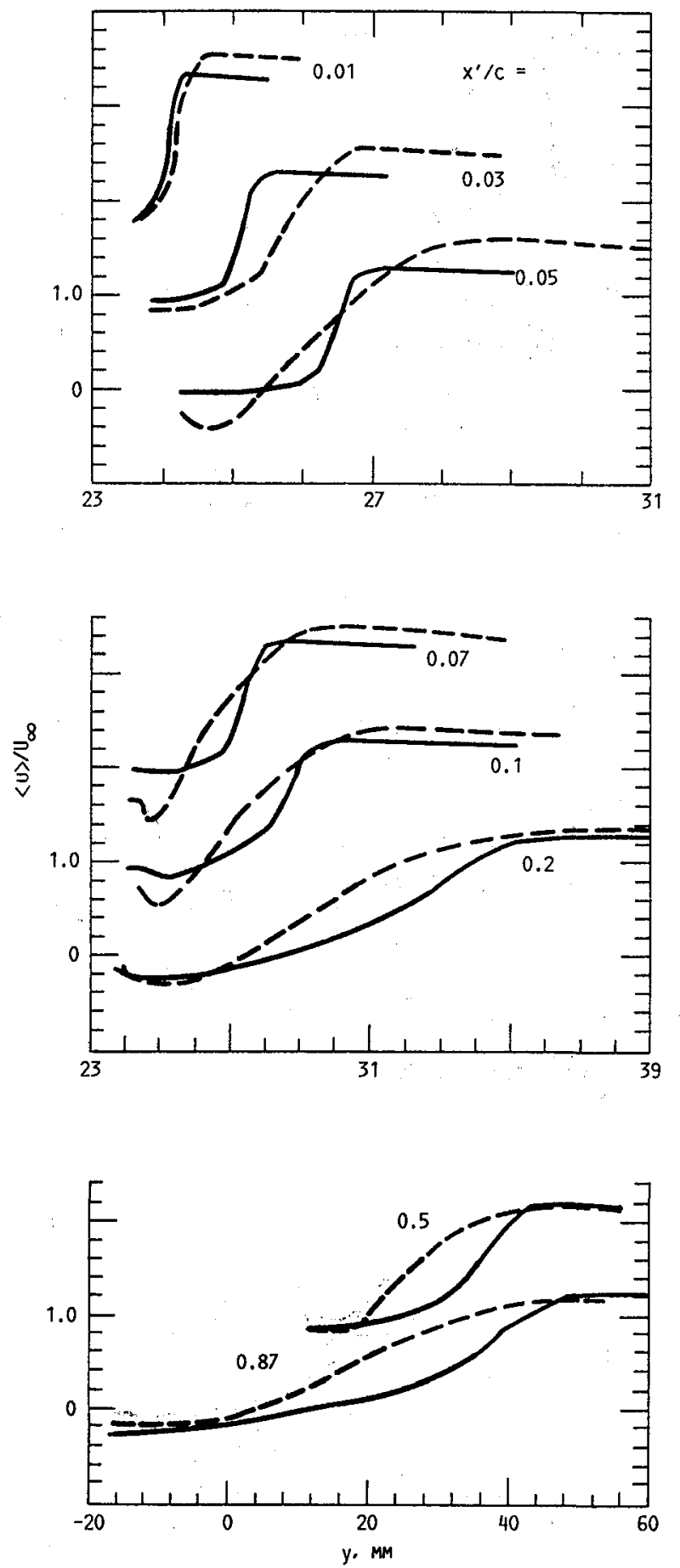

FIGURE 7. - BOUNDARY LAYER PROFILES OF $\langle U\rangle$ AT DIFFERENT $x^{\prime} / c$. SOLID LINES FOR UNEXCITED FLOW. DASHED LINES FOR EXCITATION WITH $\uparrow_{p}=342 \mathrm{~Hz}$ AND $\left\langle U_{r}^{\prime}\right\rangle / N_{\infty}=1.5$ PERCENT; $\alpha=18^{\circ}, R_{c}=75000$. IN EACH SET, ORDINATE PERTAINS TO LOWEST PAIR AND OTHER PAIRS ARE STAGGERED BY ONE MAJOR DIVISION. 

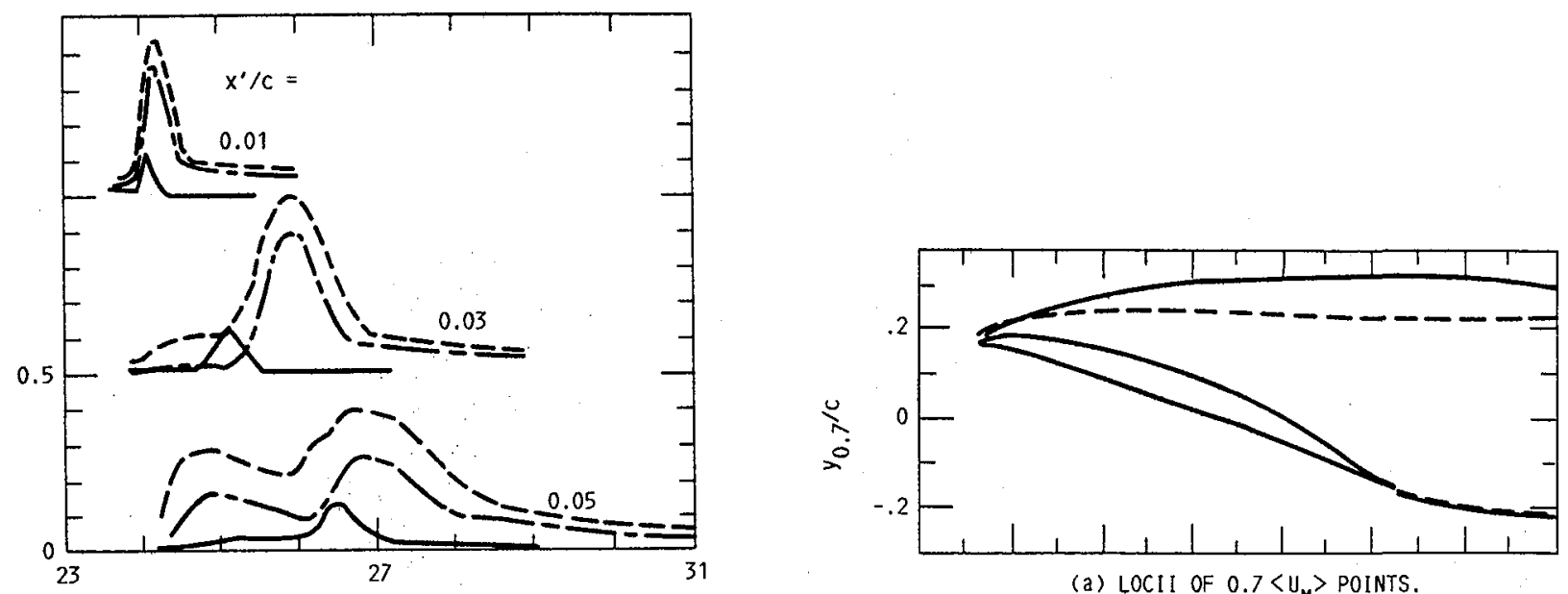

(a) LOCII OF $0.7\left\langle U_{M}\right\rangle$ POINTS.
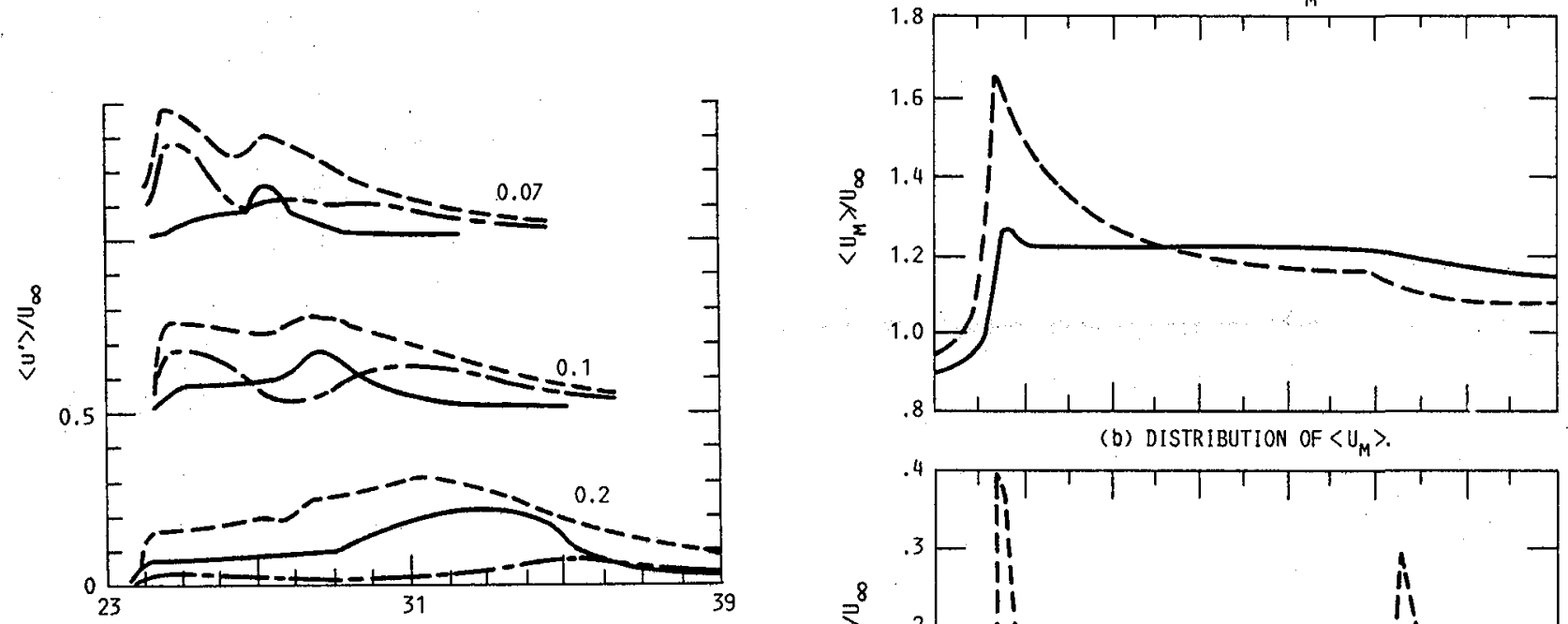

(b) DISTRIBUTION OF $\left\langle U_{M}\right\rangle$.

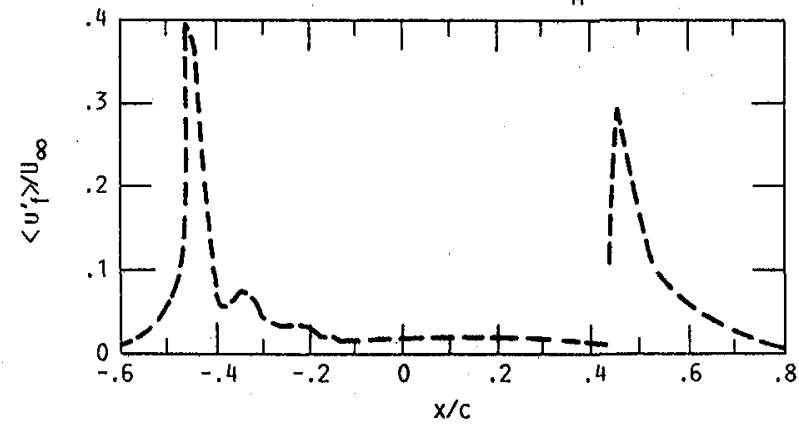

(c) FUNDAMENTAL R.M.S. AMPLITUDE AT THE $0.7\left\langle U_{M}\right\rangle$ POINTS.

FIGURE 9. - TIME AVERAGED MEAN AND FLUCTUATING VELOCITY FIELDS ON THE SUCTION SURFACE: SAME FLOW AND EXCITATION CONDITION AS IN FIG. 7. 

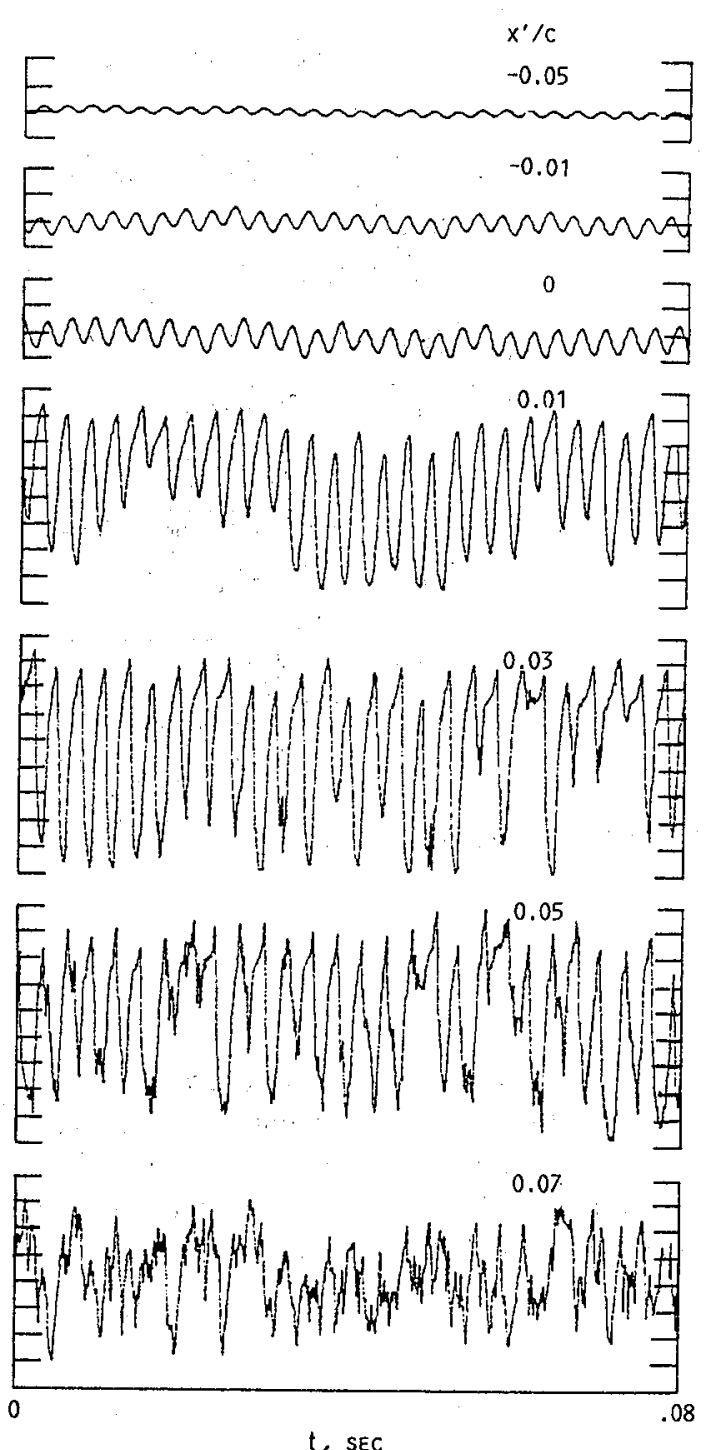

FIGURE 10. - TIME TRACES OF $\langle U\rangle$-SIGNAL AT INDICATED $x^{\prime} / C$ LOCATIONS FOR THE EXCITATION CASE OF FIG. 7. AT EACH $X^{\prime}$. THE PROBE WAS LOCATED TO APPROXIMATELY CAPTURE LARGEST FLUCTUATION AMPLITUDE.

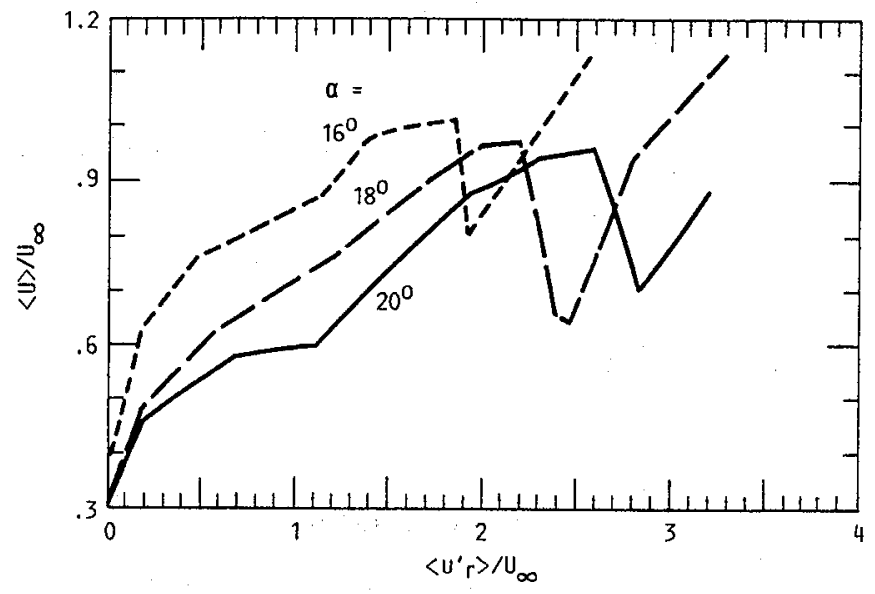

FIGURE 11, - MEAN VELOCITY AT $x^{\prime} / c=0.3$ AND ABOUT $0.1 \mathrm{c}$ ABOVE THE SURFACE, AS A FUNCTION OF EXCITATION AMPLITUDE.
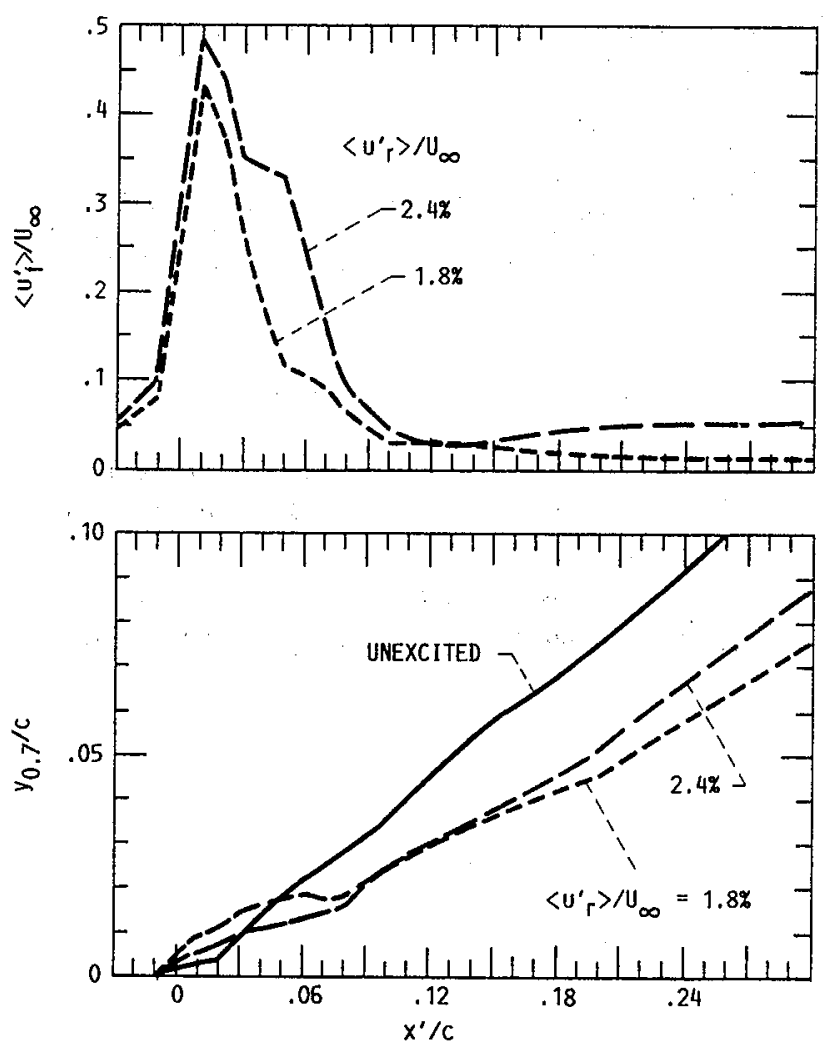

FIGURE 12. - $\left\langle U^{\circ}{ }_{f}\right\rangle$ AND THE LOCII OF $0.7\left\langle U_{M}\right\rangle$ FOR TWO EXCITATION AMPLITUDES, SAME FLOW AS IN FIGS. 7 AND 9. 


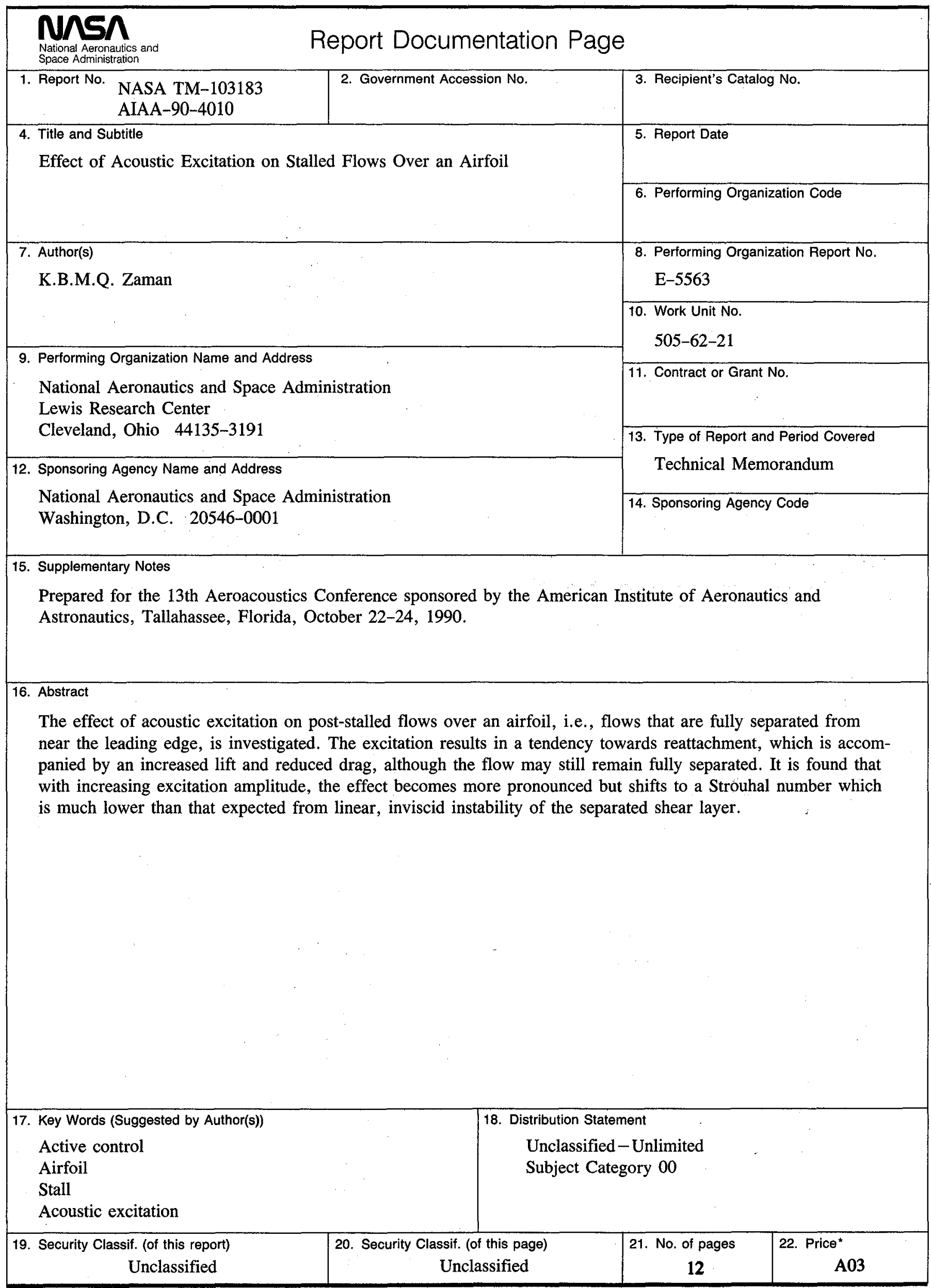

